\title{
HORMONAL MECHANISMS IN ATHEROSCLEROSIS
}

\author{
Mariana Dobrescu, Diana Păun¹, Daniel Grigorie ${ }^{1}$, Cătălina Poiană \\ "Carol Davila" University of Medicine and Pharmacy, Bucharest
}

\section{Rezumat}

Boala cardiovasculară este un proces complex care include factori genetici, inflamatori şi endocrini. În ultimele decade a fost supraestimat rolul colesterolului şi al lipidelor ca factori determinanţi în boala cardiovasculară. Cu toate acestea, se acumulează tot mai multe date despre rolul factorilor endocrini şi biochimici în procesul aterosclerozei, atât sistemic, cât şi la nivelul endoteliului vascular. Date evidente sugerează că sisteme endocrine multiple (estrogeni, androgeni, RAAS, adipokine) produc modificări cardiovasculare subtile pe parcursul dezvoltării aterosclerozei. Rămâne ca studii ulterioare să demonstreze interacţiunea acestor sisteme şi rolul lor în aterogeneză.

Cuvinte cheie: boala cardiovasculară, ateroscleroză, hormone.

\begin{abstract}
Cardiovascular disease is a complex process that includes genetic, inflammatory and endocrine components. During the last decades, much emphasis has been given to cholesterol and lipids as the primary determinants in cardiovascular disease. However, many endocrine and biochemical factors are involved in the atherosclerosis process as well, both systemically and vascular. Multiple obvious data suggest that hormones are responsible for subtle cardiovascular changes long before the development of overt atherosclerotic. Much research remains to be done regarding the interaction between endocrine systems and their role in atherogenesis.
\end{abstract}

Keywords: cardiovascular disease, atherosclerosis, hormones. 


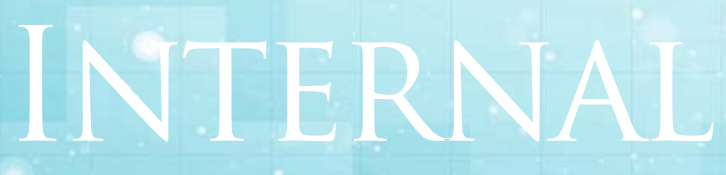

\section{General Reviews}

Cardiovascular disease is a complex process characterized by a vascular wall thickening due to the accumulation of lipids, cells and extracellular matrix between the endothelium and the smooth muscle cell layer, with the participation of multiple factors. During the last decades, studies on atherosclerosis have focused on the relationship with cholesterol and blood lipids as primary factors which are determining the cardiovascular risk.

The role of lipids in atherogenesis has been overestimated in the past, and current therapeutic strategies still involve only pharmacological interventions for the control of hyperlipidemia and lifestyle change. Despite of numerous studies, however, the relationship between cholesterol, atherosclerosis and cardiovascular disease (CVD) remains controversial.

Thus, almost $50 \%$ of the people who suffer a coronary accident do not show high cholesterol levels, and the cardioprotective effects of statins are mediated not only by simply lowering cholesterol, but are also partially explained by the lowering of arterial inflammation and the effects on vitamin D.

Therefore, numerous studies address potential contributors to CVD other than hypercholesterolemia, without there being yet a fully outlined notion of the pathophysiology of CVD. Numerous medical comorbidities, including endocrine disorders such as hypothyroidism and diabetes or psychiatric disorders such as depression, are associated with an increase of the cardiovascular risk and exhibit gender differences.

Females present more frequently episodes of depression and are more frequently diagnosed with metabolic syndrome, subclinical hypothyroidism has a higher frequency in females and it is associated with coronary artery disease, and diabetes, which is associated with CVD risk, is generally poorly controlled in females. However, all studies show that females are at lower risk of developing CVD as compared with males. Most statistics indicate that the CVD risk occurs 5-10 years later in females than is males and menopause itself occurs as a period associated with the increase of the cardiovascular risk.

Also, males with deficient estrogen action (due to genetic mutations in the estrogen receptor) develop early-onset atherosclerosis, visceral adipose tissue, hyperinsulinemia, metabolic syndrome; these same abnormalities have also been reported in males with normal estrogen action but low testosterone levels ${ }^{(1,2,3,4)}$. This has led to the deepening the contribution of genetic background and sex hormones to the development of CVD. Evidence has been gathered suggesting the role of hormonal mechanisms and it has been demonstrated 
- role in regulating vascular tone;

- role in atherogenesis (increased leptin levels);

- activation of the sympathetic NS, with a slow but progressive increase of the BP;

- increased BP mediated by effects on the central NS;

- very high leptin levels also stimulate the production of free radicals, which react with nitric oxide to create peroxynitrite, a molecule with high toxicity for the vascular endothelial cells

Table 1. Actions of leptin

- increases insulin sensitivity;

- stimulates fatty acid oxidation;

- decreases the transformation of macrophages to foam cells;

- inhibits inflammatory reactions (reduces the production of proinflammatory cytokine TNF- $\alpha$ by macrophages and decreases the expression of adhesion molecules VCAM-1, ICAM-1, selectin in the endothelial cells as response to type TNF- $\alpha$ inflammatory stimuli);

- induces endothelium-dependent NO-mediated vasodilation;

- negative regulation of angiogenesis;

- participates in the stabilization of atherosclerotic plaques by increasing the expression of TIMP-1 (Tissue Inhibitor of Metaloproteinase-1);

- regulates the lipid and glucose metabolism 


\section{INTERNAL}

\section{General Reviews}

- Vasoconstriction

- Endothelial dysfunction

- Pro-inflammatory phenotype

- Pro-thrombotic phenotype

- Remodelling

Table 3. Local pathological effects of ANG II

that estradiol and androgens are responsible for subtle cardiovascular changes long before the development of signs of overt atherosclerosis ${ }^{(5,6)}$.

\section{The role of sex hormones in CVD is} supported by multiple studies leading to the hypothesis that estrogens protect females from the complications of atherosclerosis.

The cardioprotective effects of estrogens act via multiple mechanisms:

- Female sex hormones, especially estrogens, influence the lipid profile: increase HDL, decrease LDL and LDL oxidation, control triglyceride levels (responsible for CVD manifestations for $66 \%$ compared with LDL elevation - $25 \%$, according to a Framingham study).

- Effects of estrogens on the vascular system: stimulation of angiogenesis and production of vasodilator factors (nitric oxide NO and prostacyclin PGI2) from vessel walls and lower the production of vasoconstrictor factors (endothelin-1 ET-1 and angiotensin II) by inhibiting vasoconstriction and lowering $\mathrm{BP}^{(7,8)}$.

- The effect of estrogens on BP is related to the stimulation of $\mathrm{G}$ protein secretion and calcium channel inhibition. This effect is obvious in females with surgically induced menopause, who often have an increased of peripheral vascular resistance and of the $\mathrm{BP}{ }^{(9)}$. The BP values may return to normal after initiating estrogen treatment, through the action of estradiol of decreasing sympathetic activity and its action on vasoconstrictor (angiotensin, serotonin) and vasodilator (bradykinin) mediators.

- Estrogens decrease platelet aggregation and regulate cytokines and inflammatory 
markers implicated in the antiatherosclerotic effect.

- Experimentally, estrogens interfere with the renin angiotensin aldosterone system (RAAS) and this mechanism is involved in the hypertension and the atherosclerosis associated with menopause, and estradiol treatment may counteract this effect. Therefore, estrogen therapy could be an additional protection in high-risk patients with HBP and heart failure, by counteracting the deleterious effects of angiotensin II ${ }^{(10,11,12)}$.

- Genetic polymorphisms of ER genes (ER- $\alpha$ and $E R-\beta$ ) which predominate in vascular endothelial and smooth muscle cells. Gene polymorphisms of ER- $\alpha$ gene and $E R-\beta$ gene linked with increase of CVD risk, myocardial infarction and obesity have been described. Some ER- $\alpha$ gene polymorphisms may influence the peripheral response to estradiol and, indirectly, the prevalence of menopauserelated abnormalities; ER- $\beta$ gene expression predominates in vascular smooth muscle cells and it is associated with an increase of coronary artery plaque in both females and males ${ }^{(13,14,15,16,17,18)}$.

Androgens and the relationship with the cardiovascular system are the subject of numerous studies, but the results are still inconclusive. Experimental evidence suggests that androgen deficiency contributes to the onset and progression of CVD and is associated with endothelial dysfunction, adverse lipid profile, inflammatory reaction, alteration of the vascular smooth muscle, hypertension, metabolic syndrome, and type 2 diabetes. In older males, the decrease of the total testosterone levels is predictive for the increase of the incidence of stroke, even after the correction of classic cardiovascular risk factors; the plasma testosterone level is decreased among males with CVD, suggesting a possible preventive role of testosterone therapy. Testosterone has athero-protective effects, without the participation of androgen receptors, via mechanisms related to its local conversion to estradiol in the arterial and venous system; on this pathway, in both males and females, testosterone produces vasodilation, reduces the level of pro-inflammatory cytokines, reduces the level of cholesterol and triglycerides, and improves the endothelial function ${ }^{(19,20,21)}$.

On the contrary, in young females, an increased level of androgens and estrogens can have an adverse influence on the vascular physiology. An example is polycystic ovarian syndrome, a common disorder in young females, associated with hyperandrogenism, frequently with insulin resistance, obesity, atherogenic lipid profile; at the time of menopause, females with polycystic ovarian syndrome have both increased androgen production, increased risk of metabolic syndrome and increased risk of CVD, but it is not clarified whether this risk is correlated with hyperandrogenism or the presence of other cardiovascular risk factors.

\section{Vitamin D and cardiovascular risk}

Vitamin D - a hormone involved in regulating calcium and phosphorus levels that has important autocrine and paracrine roles - is also involved in the maintenance of normal cardiovascular function.

The main source of vitamin $D$ is food, but exposure to sunlight may also increase the level of endogenous vitamin D. In the cardiovascular system, there is a wide distribution of vitamin $D$ receptors in the 


\section{INTERNAI}

\section{General Reviews}

vascular endothelium, vascular smooth muscle cells, cardiomyocytes. Mechanisms of action of vitamin $D$ at the cardiovascular level include suppression of pro-inflammatory cytokines and increase of anti-inflammatory cytokines, influences on the lipid balance with increased HDL levels, decreases the prevalence of the metabolic syndrome; interestingly, the pleiotropic effects of statins include a stimulatory effect on endogenous vitamin D.

Low serum level of vitamin $D$ is associated with adverse cardiovascular events such as HBP, obesity, DM, metabolic syndrome. Decrease of plasma vitamin D levels below 15 $\mathrm{ng} / \mathrm{mL}$ is associated with doubling the risk of a cardiovascular event such as a heart attack, heart failure, or stroke in the next 5-6 years. Furthermore, in individuals undergoing coronary angiography, low levels of vitamin D is associated with an increase in mortality within 7-8 years, compared with patients with higher vitamin D levels ${ }^{(22,23,24,25,26)}$.

\section{The role of adipocytes}

Obesity is associated with increased cardiovascular mortality and morbidity. It induces vascular endothelial dysfunction, which is central to the pathogenesis of atherosclerosis and predictive for the cardiovascular risk; central obesity is associated with increased insulin resistance, type 2 DM, dyslipidemia, and CVD. Adipose tissue is not simply an energy storage organ, but also a secretory organ that secretes adipokines and cytokines; through these bioactive substances it is involved in the pathogenesis of atherosclerosis and the development of cardiovascular complications. Leptin is a hormone secreted by the adipocytes in direct proportion to the amount of adipose tissue present. It has an anorexigenic effect ("satiety hormone") and increases metabolic rate, thus contributing to weight loss; leptin is also involved in glucose metabolism, as well as in normal sexual maturation and reproduction. Leptin interacts with the cardiovascular system in multiple ways ${ }^{(27,28)}$ :

Leptin is considered to be a significant predictor for coronary events - e.g. the positive relationship between plasma leptin levels and coronary calcifications in asymptomatic non-diabetic patients has been demonstrated. The excess of leptin in obesity participates in the pathophysiology of hypertension through multiple mechanisms: stimulates sympathetic SN activity, amplifies insulin resistance, stimulates RAAS activity, modulates endothelial cell function (vascular remodelling), effects on tubular reabsorption of $\mathrm{Na}$.

Adiponectin is an adipokine with antiatherosclerotic effects, produced in lower 


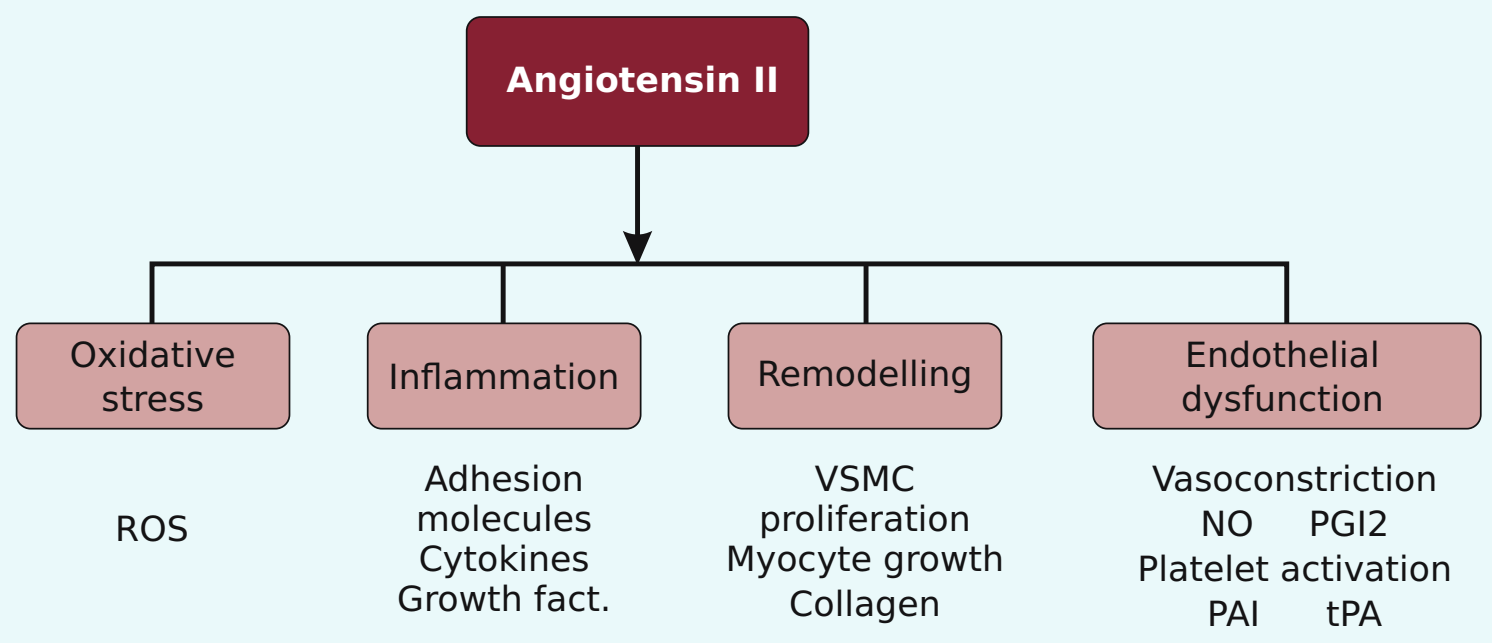

Figure 1. Actions of ANG II

\section{ANG II}

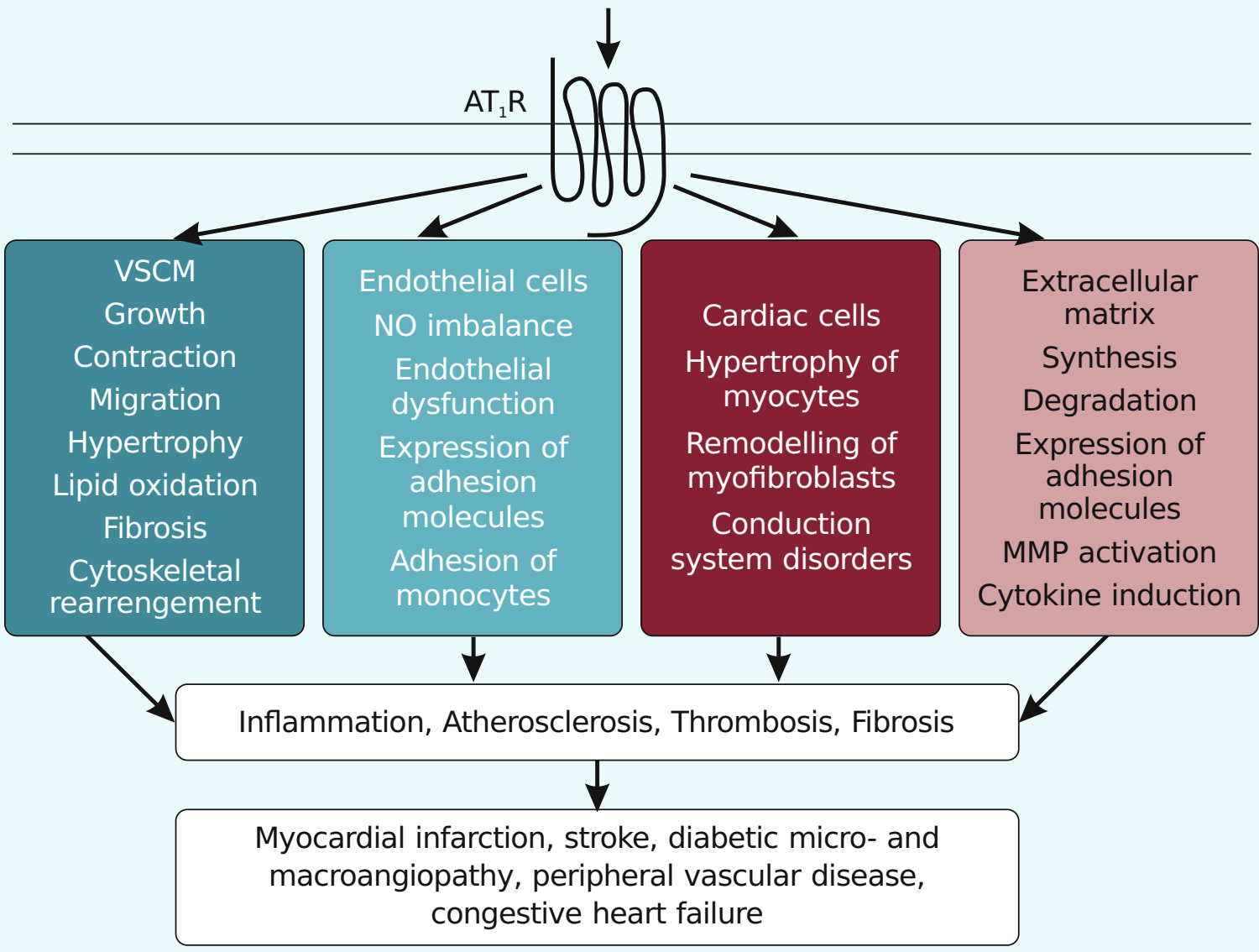

Figure 2. Role of ANG II in cardiovascular pathology. ANG II triggers signalling in VSMC, endothelial cells, cardiac fibroblasts and extracellular matrix 


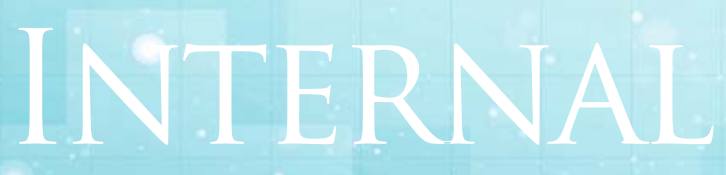

General Reviews

amounts than leptin. The adiponectin receptors are present on endothelial cells and the anti-atherogenic action of adiponectin has been correlated with numerous mechanisms $^{(29)}$.

Resistin is a hormone produced almost exclusively by adipose tissue matrix, which induces inflammation and insulin resistance.

The increase of the resistin level is associated with type 2 DM, has effects on myocardial cells, decreasing their ability to contract and has been evaluated to be a strong predictor of heart failure risk; resistin is associated with HBP, insulin resistance, endothelial dysfunction, chronic inflammation, and accelerated atherogenesis ${ }^{(30.31)}$.

Homocysteine is considered an independent risk factor for the development of atherosclerosis, as well as for arterial and venous thrombosis.

Hyperhomocysteinemia leads to endothelial injury and dysfunction via generation of free radicals (experimental data), stimulates vascular smooth muscle cell proliferation and collagen deposition in the atheromatous plaque and inhibits vascular endothelial cell growth. In addition, elevated homocysteine levels may promote thrombosis by increased thrombin generation and endothelial cell sensitization to the effect of inflammatory mediators; also favours the excessive adhesion of monocytes to the vascular endothelium ${ }^{(32)}$.

\section{ANG II and atherosclerosis}

RAAS was classically known as a circulating hormone system, that regulates the arterial tone and $\mathrm{BP}$, aldosterone release and $\mathrm{Na}+$ reabsorption; RAAS was thought to produce cardiovascular disease via hemodynamic and endocrine pathways, via vasoconstriction and increase of the intravascular volume, with increase of pump capacity of the heart. In the last decades it has been demonstrated that RAAS, via its effector angiotensin II (ANG II), is an important pro-atherosclerotic mediator, that together with aldosterone activates cell signalling pathways promoting atherogenesis, remodelling and prothrombotic status.

It has been demonstrated that locally formed ANG II acts as an atherogenic agent, activating numerous substances, including growth factors, cytokines, chemokines and adhesion molecules, involved in growth/apoptosis, fibrosis and inflammation, and also contributes to plaque rupture in vulnerable plaques.

ANG II is involved in blood coagulation and the pathogenesis of acute thrombosis via multiple mechanisms. Within the atherosclerotic plaque and inflamed vascular endothelium, monocytes and macrophages may synthesize additional ANG II, continuing the cycle of coagulation ${ }^{(33,34,35)}$. The role of ANG II in the inflammation process in 
atherosclerotic is supported by multiple evidences $^{(36,37)}$.

- ACE is abundantly expressed in vulnerable lesions, especially in foam cells and endothelial cells.

- ACE activity is significantly increased in coronary lesions (after atherectomy) in patients with acute coronary syndrome compared with a stable ischemic heart disease. ACE is involved in endothelial dysfunction, and ACE inhibitors improve endothelial function measured by flowmediated dilation in the brachial artery.

- Transgenic studies demonstrated the atherogenic effect of ANG II and the antiatherogenic effect of ACE inhibitors;

- In human atherosclerotic lesions RAS is locally activated, presenting high levels of ACE, ANG II and AT1 receptors.

- ANG II peptide fragments, such as ANG IV, may counteract the development of endothelial dysfunction by increased NO production. ACE2 is another antiatherogenic compound, that inactivates the pro-atherogenic ANG II.

lock the action of ANG II, such as ACE inhibitors and angiotensin receptor antagonists, are currently used in the treatment of HBP, cardiac failure, atherosclerosis and other cardiovascular diseases. Human and animal trials indicated the beneficial effect of RAAS inhibitors on cardiovascular aggression, with reduction of inflammatory response, cell proliferation and fibrosis.

Under physiological conditions, ANG II is of major importance in the cardiovascular system and participates minute by minute in the adjustment of space adaptation. After binding to AT1 receptors, ANG II rapidly activates (seconds, minutes) mechanisms that produce VSMC (vascular smooth muscle cells) contraction, maintaining the vascular tone. ANG II stimulates aldosterone synthesis and secretion and increases the renal reabsorption of $\mathrm{Na}+$, acts on the central nervous system, and through these mechanisms is involved in maintaining sympathetic vascular tone and in selfregulation of cerebral blood flow. Thus, ANG II is essential in the integration of complex mechanisms that maintain blood pressure and perfusion of vital organs.

In case of RAS balance disorder (due to genetic or environmental factors) pathological effects of ANG II occur. RAAS stimuli are at the same time cardiovascular risk factors, such as: salt intake, stress, smoking, HBP, insulin resistance, lipidderived factors that can stimulate aldosterone synthesis, but also local production of ANG II and aldosterone, in the cardiovascular structures.

Under pathological conditions, ANG II becomes a local mediator of cardiovascular injury through its local effects ${ }^{(38,39)}$.

After prolonged exposure to ANG II its cytokine-like effects usually occur, which promote oxidative stress, cell proliferation and migration, extracellular matrix deposits, thickening of vessel walls and perivascular fibrosis, vascular remodelling and finally organ damage. In this way, ANG II is involved in the pathogenesis of atherosclerosis and the development of aneurysms ${ }^{(40,41,42,43,44)}$.

- ANG II induces imbalances between the vasodilator factors and vasoconstrictor factors: it mediates oxidative stress and reduces the activity of NO, and the imbalances between $\mathrm{NO}$ and ROS promotes vasoconstriction, has proinflammatory and pro-thrombotic effects.

- ANG II induces endothelial dysfunction and activates the pro-inflammatory phenotype in the VSMC; the pro- 


\section{INTERNAL}

\section{General Reviews}

inflammatory action of ANG II on the vascular wall is synergic with the action of other factors of vascular risk (dyslipidemia, diabetes, smoking).

- ANG II is involved in vascular remodelling, increases the expression of autocrine growth factors in the VSMC, modulates the migration of vascular cells, reduces apoptosis of the VSMC, alters the composition of the extracellular matrix.

- ANG II causes $n$ imbalance between the fibrinolytic and coagulation systems, stimulates the synthesis of PAI-1 and reduces the production of TPA, with alteration of the TPA/PAI-1 ratio in favour of PAI-1 and the development of a new prothrombotic status.

In conclusion, studies conducted in last decades demonstrated that formed locally (in the tissue) ANG II is involved in growth/apoptosis, fibrosis and inflammation; a new notion has been outlined on ANG as a pro-inflammatory mediator, which induces directly the formation of the atherosclerotic plaque and remodelling .

This cascade of events, together with the abnormalities produced in the coagulation system, leads to atherosclerosis and thrombosis. The combination of these mechanisms leads to pathological conditions such as hypertension, atherosclerosis, restenosis, heart failure, chronic kidney disease, insulin resistance, tumour progression. It is considered that ACE inhibitors could bring benefits in patients with many risk factors, and in contrast their effects could be modest in patients with few risk factors and in those who receive treatment with statins and platelet antiaggregant agents.

Currently new therapeutic targets are developed for blocking various components of the RAS, and subsequent studies are focused on the development of therapeutic strategies targeting morbidity and mortality due to cardiovascular diseases.

\section{Aldosterone}

Current data regarding the actions of aldosterone (Aldo) are in strong contrast with the classical notions which has considered this hormone as being involved only in the homeostasis of electrolytes and water, mediated by the kidneys via the $\mathrm{Na}$ and $\mathrm{K}$ channels, and the increase of the BP on the pathway of the regulation of ionic balance. During the last decades many evidence were accumulated supporting the direct effects of Aldo on the vascular system, independent of the blood pressure.

It was demonstrated that Aldo influences the vascular contraction indirectly via the membrane receptors and on the pathway of vascular sensitisation to vasoconstrictor agents, or directly via effects of pro- 
inflammatory type with vascular remodelling (in the presence of salt excess). Additionally it mediates effects attributed to ANG II such as vascular remodelling, endothelial dysfunction, inflammation, and increase in blood pressure. Aldo has direct effects in the vascular endothelium and the vascular smooth muscle cells, and leads to histological and functional changes ${ }^{(45,46,47,48)}$.

- In the vascular endothelium it influences the vasodilator and vasoconstrictor mechanism which are endotheliumdependent directly or via ANG II: Aldo reduces the endothelium-dependent vasodilation and produces vasoconstriction via the increase of the oxidative stress in the vascular wall (an effect decreased by spironolactone).

- In the VSMC, Aldo mediates and amplifies effects of ANG II. The relationship between Aldo and ANG II in the VSMC was demonstrated experimentally and is favourably influenced by spironolactone or eplerenone: up-regulates the ANG II receptors, increases the level of tissue ACE with the increase of the local production of ANG II and the exacerbation of vascular injury (an effect dependent on the Aldo level and decreased by spironolactone).

Major histological abnormalities produces by the Aldo excess include perivascular fibrosis and inflammatory response.

The pro-fibrotic action of Aldo manifests itself only in the presence of low-sodium diet, is produced by the local effects of Aldo and was studied in models of hypertension and hyperaldosteronism.

Aldo is a pro-inflammatory hormone which produces perivascular inflammation - studied in the intramural coronary arteries, kidneys and central nervous system. Increase of inflammatory biomarkers is significant in hyperaldosteronism and this is correlated with the increased cardiovascular risk, endothelial dysfunction, cardiac fibrosis, risk of myocardial infarction, stroke, atrial fibrillation. In the central nervous system, the Aldo excess is associated with perivascular inflammatory changes and sometimes the development of cerebral aneurysms and risk of brain hemorrhage. All these evolutions can be prevented via the administration of spironolactone or eplerenone. The Profibrotic and pro-inflammatory action of Aldo is associated with the incidence of thrombotic an arteriolar proliferative lesions in animal models.

Besides the histological changes, the Aldo excess is associated with vascular functional changes and particularly endothelial dysfunction. Aldo induces endotheliumdependent vasodilation via the inhibition of NO release and effects on the vascular matrix with the increase of the content of collagen/fibrosis, decrease of arterial compliance, tendency to vasoconstriction and decrease of baroreflex activity, followed by the decrease of the autonomous control of cardiovascular functions.

The pro-thrombotic effect of Aldo is an additional worsening factor for severe cardiovascular events and it was demonstrated particularly in chronic increase of the Aldo serum level. Experimentally, the chronic administration of Aldo potentiates thrombotic microangiopathy and thrombosis after arterial injury; this effect is blocked by spironolactone. The administration of Aldo produces thrombosis mediated by multiple mechanisms:

- reduction of fibrinolysis with decrease of tPA (tissue plasminogen activator), increase of PAl-1 (plasminogen activator inhibitor-1); 


\section{INTERNAI}

\section{General Reviews}

- alteration of platelet function;

- endothelial dysfunction, with increase of oxidative stress and platelet adhesion;

- increase of Aldo-dependent $\mathrm{K}+$ excretion (experimentally the opposite - the increase of plasma $\mathrm{K}+$ inhibits the thrombosis risk and decreases the platelet aggregation);

- effects mediate on the ANG II pathway with decrease of $\mathrm{t}$-PA and increase of PAI-1.

In the clinic the circadian variation of the Aldo secretion were studied with a major morning peak which is associated with morning increases of the BP and hemostatic changes related to the decrease of fibrinolysis and increase of platelet aggregation. These associations suggest the existence of correlations between circadian variations of Aldo, thrombotic disorders and acute cardiovascular events.

For example, the plasma aldosterone level significantly increases intraoperatively and postoperatively in relationship with the electrolyte dysregulations and the RAAS changes; it was suggested that the thrombotic events occurring in relationship with surgery would be a consequence of "operative hyperaldosteronism".

Also the venous stasis is generally associated with the increase of plasma Aldo and it is considered that Aldo could have a role in the hemostasis disturbances from the venous stasis in prolonged immobilizations, congestive heart disease, obesity.

In conclusion, the Aldo excess has a central role in the pathogenesis of cardiovascular pathology in general, and particularly in atherosclerosis, vascular remodelling and HBP. The increase of Aldo level promotes oxidative stress, endothelial dysfunction, vascular inflammation, increase of the expression of adhesion molecules, and has a pro-thrombotic effect. This process can by prevented via administration of eplerenone. The structural and functional changes induced by Aldo in the target tissues are also responsible for the poor evolution of atherothrombotic lesions, HBP, heart failure and other pathophysiological states.

\section{Conclusions and perspectives}

Multiple current data demonstrate that atherosclerosis is a complex process which includes genetic, inflammatory and endocrine factors. Thus many studies on the pathogenesis of the cardiovascular aggression address other potential contributors different than hypercholesterolemia. The cardiovascular effects of the hormone therapies are intensely studied and new therapeutic effects targeting various hormone changes are analysed ${ }^{(13)}$. However there is no completely outlined notion yet regarding the pathophysiology of the cardiovascular disease. 
The estrogen replacement therapy is based on human and animal studies which support the conclusion that endogenous estrogens have a protective role in premenopausal females, and estrogenic therapy has important favourable effects in early stages of atherosclerosis in young post-menopausal females.

Conversely estrogenic treatment in females aged over 65 years old with coronary atherosclerotic lesions which are already developed has no beneficial effects. Lack of compliance for estrogen replacement therapy, usually out of fear of breast cancer, remains a major problem. Therefore the effects of co-administration of a preventive agent against breast cancer (e.g. SERMselective estrogen receptor modulators; phytoestrogens) together with low doses of estrogens is studied ${ }^{(49,50,51,52,53)}$.

\section{Contraceptive hormone therapy}

A wide range of human and animal studies suggest favourable conclusions regarding the anti-atherosclerotic effects of contraceptive hormone therapy. However current guidelines advise caution in the administration of hormone contraceptives in women under the age of 35 years who have associated cardiovascular risk factors such as HBP, dyslipidemia, DM, smoking, and obesity. After the age of 35 years, guidelines contraindicate the administration of hormone contraceptives in women who have these associated cardiovascular risk factors. During this therapy the risk of myocardial infarction, arrhytmias and venous thromboembolism was signalled, particularly in women with obesity or smoking. Current guidelines recommend, as with any other medication, the selecting and analysing of the benefit-risk ratio in every patient before the initiation of contraceptive hormone therapy ${ }^{(54,55)}$.
Androgen deprivation therapy addresses males with prostate cancer and is more commonly associated with the development of the atherosclerotic disease and the increase or cardiovascular morbidity and mortality risk, via multiple mechanisms:

- metabolic effects mimicking metabolic syndrome: hyperglycaemia, dyslipidaemia, obesity;

- direct local effects with modulation of local inflammatory response and development of atherosclerotic plaque, possibly plaque rupture and thrombosis.

Isoflavone diet was the subject of many studies starting from the possible potential role in prevention of coronary artery disease and other chronic diseases. The physiological role of the bioactive compounds from plants raised the interest in the last decades, most studies focusing on flavonoids and particularly their subclass- phytoestrogens. Phytoestrogens, plant-derived non-steroidal compounds, of which isoflavones were particularly studied, have an estrogen-like activity. It was demonstrated that diets rich in soy products, with a high isoflavone content, are associated with a decreased incidence of coronary artery disease. The biological effects of isoflavones are dependent on multiple factors, including the dose and the duration of the intake, the affinity of protein binding, individual metabolism, and intrinsic estrogenic level. Experimental studies on cell cultures and animal studies indicated the effect of isoflavones to prevent or delay atherogenesis via multiple mechanisms ${ }^{(56,57,58)}$.

Most researchers still support the need to deepen these studies for stable conclusions on the favourable effect of isoflavones, to determine the optimal dose, in specific population groups, and various age groups. 


\section{INTERNAL MEI}

\section{General Reviews}

- antioxidative action with stimulation of antioxidative enzymes, decrease of LDL-cholesterol level, and inhibition of oxidation of LDL-cholesterol particles;

- improvement of vascular reactivity;

- production of nitric oxide;

- inhibition of pro-inflammatory cytokines, of adhesion factors;

- inhibition of platelet aggregation.

Table 3. Local pathological effects of ANG II

RAAS inhibition is assessed for antiatherosclerotic effects with decrease of plaque progression and ischemic events. It was demonstrated that drugs which inhibit the action of ANG II improves the cardiovascular aggression, decrease the inflammatory response, cell proliferation and fibrosis, and the administration of spironolactone or eplerenone has favourable effects independent by the decrease of the BP.

Currently new therapeutic targets are studied for blocking the various components of the RAAS, but also the interaction between RAAS and hyperlipidemia. Many studies are referring to new components of the RAAS, the biological degradation products of ANG II are studied, the role of ACE2 with a negative feedback effect on activated RAS, the polymorphism of $A T_{1}$ and the impact of $A T_{1} / A T_{2}$ in atherogenesis.

In conclusion, many endocrine systems are involved in the process of atherogenesis and their progressive knowledge will open new therapeutic perspectives for the prevention of the complications in cardiovascular disease; further studies are necessary about hormone therapy for the antiatherogenic protection.

\section{References}

1. Bittner V. Menopause, age, and cardiovascular risk: a complex relationship. J Am Coll Cardiol. 2009; 54(25):2374-5.

2. Magnani JW, Moser CB, Murabito JM, et al. Age of 
natural menopause and atrial fibrillation: the Framingham Heart Study. Am Heart J. 2012; 163(4):729-34. 3 Vaidya D, BeckerDM,

3. Bittner V, Mathias RA, Ouyang P. Ageing, menopause, and ischaemic heart disease mortality in England, Wales, and the United States: modelling study of national mortality data. BMJ. 2011; 343:d5170.

4. Malkin CJ, Pugh PJ, Jones RD, Jones TH, Channer KS. Testosterone as a protective factor against atherosclerosis--immunomodulation and influence upon plaque development and stability. J Endocrinol. 2003; 178(3):373-80.

5. Phillips GB. Is atherosclerotic cardiovascular disease an endocrinological disorder? The estrogen-androgen paradox. J Clin Endocrin Metab. 2005; 90(5):2708-2711.

6. Burke A.P., Farb A., Malcom G., Virmani R.. Effect of menopause on plaque morphologic characteristics in coronary atherosclerosis, Am Heart J, 2001; vol. 141 2:58-62.

7. Rossouw JE, Prentice PL, Manson JE, et al. Postmenopausal hormone therapy and risk of cardiovascular disease by age and years since menopause. JAMA. 2007; 297(13):1465-1477.

8. Peter I, Kelley-Hedgepeth A, Huggins GS, et al. Association between arterial stiffness and variations in oestrogen-related genes. J Hum Hypertens. 2009; 23(10):636-644.

9. Debing E, Peeters E, Duquet W, Poppe $K$, Velkeniers $B$, Van den Brande $P$. Endogenous sex hormone levels in postmenopausal women undergoing carotid artery endarter-ectomy. EurJ Endocrinol. 2007; 156(6):687-693 10. Austin C.E.. Chronic and acute effects of oestrogens on vascular contractility, J Hypertens, 2000, vol. 18:1365-1378.

11. HigashiY., Sanada M., Sasaki S., et al. Effect of estrogen replacement therapy on endothelial function in peripheral resistance arteries in normotensive and hypertensive postmenopausal women, Hypertension, 2001; vol. 37:651-657.

12. Bechlioulis A, Naka KK, Calis KA, et al. Cardiovascular Effects of Endogenous Estrogen and Hormone Therapy. Curr Vasc Pharmacol. 2010; 8:249-258.

13. Badimon, L. New challenges in the etiopathogenesis of atherothrombosis. Cerebrovasc Dis 11 Suppl 1. 2001;8084.

14 Hodges Y.K., Tung L., Yan X.D., Graham J.D., Horwitz K.B., Horwitz L.D..Estrogen receptors alpha and beta: prevalence of estrogen receptor beta MRNA in human vascular smooth muscle and transcriptional effects. Circulation, 2000; vol.101:1792-1798.

15. Shearman AM, Cooper JA, Kotwinski PJ, et al. Estrogen receptor alpha gene variation is associated with risk of myocardial infarction in more than seven thousand men from five cohorts. Circ Res. 2006; 98(5):590-592.
16. Hodges $Y K$, Tung $L$, Yan XD, Graham JD, Horwitz KB, Horwitz LD. Estrogen receptors alpha and beta: prevalence of estrogen receptor beta MRNA in human vascular smooth muscle and transcriptional effects. Circulation. 2000; 101(15):1792-1798.

17. Schuit SC, Oei HH, Witteman JC, et al. Estrogen receptor alpha gene polymorphisms and risk of myocardial infarction. JAMA. 2004; 291(24):2969-2977.

18. Schuit SC, de Jong FH, Stolk L, et al. Estrogen receptor alpha gene polymorphisms are associated with estradiol levels in postmenopausal women. Eur J Endocrinol. 2005; 153(2):327-334.

19. Malkin CJ, Pugh PJ, Jones RD, Jones TH, Channer KS. Testosterone as a protective factor against atherosclerosis--immunomodulation and influence upon plaque development and stability. J Endocrinol. 2003; 178(3):373-80.

20. Liu PY, Death AK, Handelsman DJ. Androgens and cardio-vascular disease. Endocr Rev. 2003; 24(3):313340.

21. Yeap BB, Hyde Z, Almeida OP, et al. Lower testosterone levels predict incident stroke and transient ischemic attack in older men. J Clin Endocrinol Metab. 2009; 94(7):2353-2359.

22. Gonzalez-Clemente JM, Gimenez-Palop O, Vilardell C, Caixas A, Gimenez-Perez G. Are statins analogues of vitamin D? Lancet. 2006; 368(9543):1233.

23. Perez-Castrillon JL, Vega G, Abad L, et al. Effects of atorvastatin on vitamin $D$ levels in patients with acute ischemic heart disease. Am J Cardiol. 2007; 99(7):903905.

24. Michos ED, Melamed ML. Vitamin $D$ and cardiovascular disease risk. Curr Opin Clin Nutr Metab Care. 2008; 11(1):7-12.

25. Giovannucci E, Liu Y, Hollis BW, Rimm EB. 25hydroxyvitamin $D$ and risk of myocardial infarction in men:a prospective study. Arch Intern Med. 2008; 168(11):1174-1180.

26. Pilz S, Dobnig $H$, Nijpels $G$, et al. Vitamin $D$ and mortality in older men and women. Clin Endocrinol (Oxf). 2009; 71(5):666-672.

27. Wannamethee SG, Tchernova J, Whincup $P$, et al. Plasma leptin: associations with metabolic, inflammatory and haemostatic risk factors for cardiovascular disease. Atherosclerosis. 2007; 191(2):418-426.

28. Wolk R, Berger P, Lennon RJ, Brilakis ES, Johnson BD, Somers VK. Plasma leptin and prognosis in patients with established coronary atherosclerosis. J Am Coll Cardiol. 2004; 44(9):1819-1824

29. Kizer J, Barzilay JI, Kuller LH, Gottdiener JS. Adiponectin and risk of coronary heart disease in older men and women. J Clin Endocrin Metab. 2008; 93(9):3357-3364. 


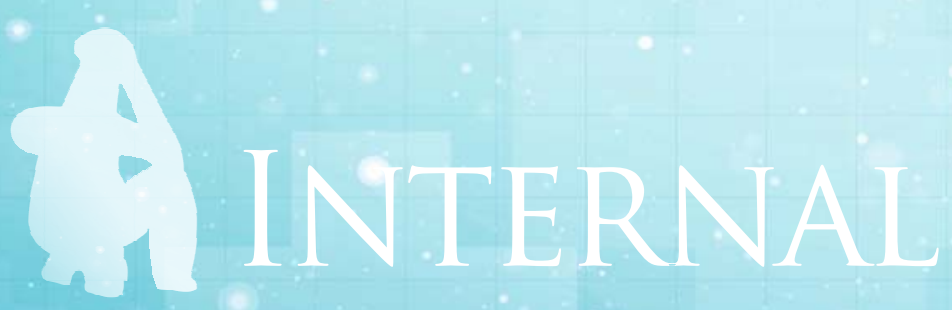

General Reviews

30. Butler J, Kalogeropoulos A, Georgiopoulou V, et al, for the Health ABC Study. Serum resistin concentrations and risk of new onset heart failure in older persons: the health, aging, and body composition (Health $A B C$ ) study. Arterioscler Thromb Vasc Biol. 2009; 29(7):1144-1149.

31. Frankel DS, Vasan RS, D'Agostino RB Sr, et al. Resistin, adiponectin, and risk of heart failure the Framingham offspring study. J Am Coll Cardiol. 2009; 53(9):754-762.

32. Bonaa K, Njolstad I, Ueland P. NORVIT trial investigators. Homocysteine lowering and cadiovascular evens after acute myocardial infarction. N Engl J Med. 2006; 354(15):1578-1588.

33. Shi RZ, Wang JC, Huang SH, Wang XJ, Li QP. Angiotensin II induces vascular endothelial growth factor synthesis in mesenchymal stem cells. Exp Cell Res. 2009; 315(1):10-15.

34. Shan H, Bai X, Chen X. Angiotensin II induces endothelial cell senescence via the activation of mitogen-activated protein-kinases. Cell Biochem Funct. 2008; 26(4):459-466.

35. Javeshghani $D$, Sairam MR, Neves MF, Schiffrin EL, Touyz RM. Angiotensin II induces vascular dysfunction without exacerbating blood pressure elevation in a mouse model of menopause-associated hypertension. J Hypertens. 2006; 24(7):1365-1373.

36. Vinh A, Widdop RE, Drummond GR, Gaspari TA. Chronic angiotensin IV treatment reverses endothelial dysfunction in ApoE-deficient mice. Cardiovasc Res. 2008; 77(1):178-187.

37. Sluimer JC, Gasc JM, Hamming l, et al. Angiotensinconverting enzyme 2 (ACE2) expression and activity in human carotid atherosclerotic lesions. J Pathol. 2008; 215(3):273-279.

38. Jacoby DS, Rader DJ. Renin-angiotensin system and atherothrombotic disease: from genes to treatment. Archives of Internal Medicine. 2003 ; 163(10):1155-1164.

39. Fyhrquist $F$, Saijonmaa $O$. Renin-angiotensin system revisited. Journal of Internal Medicine. 2008; 264(3):224-236.
40. Toko $H$, Zou $Y$, Minamino $T$, Masaya M, Harada $M$, Nagai $T$, Sugaya $T$, Terasaki $F$, Kitaura $Y$, Komuro $I$. Angiotensin II type 1 a receptor is involved in cell infiltration, cytokine production, and neovascularization in infarcted myocardium. Arterioscler Thromb Vasc Biol. 2004; 24:664-670.

41. Singh VP, Le B, Khode R, Baker KM, Kumar $R$. Intracellular angiotensin II production in diabetic rats is correlated with cardiomyocyte apoptosis, oxidative stress, and cardiac fibrosis. Diabetes. 2008; 57(12):3297-3306.

42. Singh VP, Baker KM, Kumar R. Activation of the intracellular reninangiotensin system in cardiac fibroblasts by high glucose: role in extracellular matrix production. American Journal of Physiology. 2008; 294(4):H1675-H1684.

43. Kumar R, Singh VP, Baker KM. The intracellular reninangiotensin system: implications in cardiovascular remodeling. Current Opinion in Nephrology and Hypertension. 2008; 17(2):168-173.

44. Schmieder RE, Hilgers KF, Schlaich MP, Schmidt BM. Reninangiotensin system and cardiovascular risk. The Lancet. 2007; 369(9568):1208- 1219.

45. Connell JM, MacKenzie SM, Freel EM, Fraser R, Davies E. A lifetime of aldosterone excess: long-term consequences of altered regulation of aldosterone production for cardiovascular function. Endocr Rev. 2008; 29(2):133-154.

46. Francis GS, Tang WH. Should we consider aldosterone as the primary screening target for preventing cardiovascular events? J Am Coll Cardiol. 2005; 45:12491250.

47. Stowasser M. New perspectives on the role of aldosterone excess in cardiovascular disease. Clin Exp Pharmacol Physiol. 2001; 28:783-791.

48. Marney, A. M., and Brown, N. J. Aldosterone and endorgan damage. Clin. Sci. (Lond.) 2007; 113:267-278.

49. Turgeon J, McDonnell D, Martin K, Wise P. Hormone therapy: physiological complexity belies therapeutic simplicity. Science. 2004; 304(5676):1269-1273.

50. Manson JE, Allison MA, Rossouw JE, et al. Estrogen 
therapy and coronary-artery calcification. N Engl J Med. 2007; 356(25):2591-2602.

51. Rossouw JE, Prentice PL, Manson JE, et al. Postmenopausal hormone therapy and risk of cardiovascular disease by age and years since menopause. JAMA. 2007; 297(13):1465-1477.

52.Herrington D.M., Reboussin D.M., Brosnihan K.B., et al. Effects of estrogen replacement on the progression of coronary-artery atherosclerosis, N EnglJ Med. 2000; vol. 343:522 -529.

53. Manson JE, Allison MA, Rossouw JE, et al, Estrogen therapy and coronary-artery calcification. N Eng J Med. 2007; 365:2591-2602.

54. Tanis BC, V M, Kemmeren JM, Cats VM, Helmerhorst FM, Algra A, Van Der Graaf $Y$, Rosendaal FR. Oral
Contraceptives and the Risk of Myocardial Infarction. N EnglJ Med. 2001; 345:1787-93.

55. Lidegaard O. Smoking and use of oral contraceptives: impact on thrombotic diseases. Am J Obstet Gynecol. 1999; 180:S357-63.

56. Mitchell, J.H. et al. Antioxidant efficacy of phytoestrogens in chemical and biological model systems. Arch Biochem Biophys. 1998; 360:142-148.

57. Kirk, E.A. et al. Dietary isoflavones reduce plasma cholesterol and atherosclerosis in C57BL/6 mice but not $L D L$ receptor-deficient mice. J Nutr. 1998; 128, 954959.

58. Anthony, M.S., Clarkson, T.B. and Williams, J.K. Effects of soy isoflavones on atherosclerosis: potential mechanisms. AmJ Clin Nutr. 1998; 68, 1390S-1393S. 